\title{
Establishing a Methodology for the Assessment of Remnant Stability Using Recorded Seismic Events on Harmony Mines
}

\author{
P.J. Le Roux Brentley Lucas and Associates (Pty) Ltd, and University of the Witwatersrand, South Africa \\ T.R. Stacey University of the Witwatersrand, South Africa
}

\begin{abstract}
Within the Free State province in South Africa, when mining remnants (tabular blocks of ground), the hazard of exposure to large magnitude seismic events is of great concern. It has been found, however, that damage occurs when the local magnitude of these seismic events, $M_{L} \geq 1.5$. When analysing the stress state within the remnant at the time of each seismic event, it has been found that there is a strong correlation between the stress states, which can be described by a Remnant Failure Index (RFI), based on the Mohr-Coulomb failure criterion. To evaluate remnants for possible violent failure, the newly developed RFI enables the practitioner to model proposed mining layouts for the remnant, identify possible areas within the remnant where failure can occur and identify the mining step at which it is expected to happen. This paper discusses a methodology for the assessment of remnant stability using seismic event back-analysis.
\end{abstract}

\section{Introduction}

Twenty four percent of mining that is currently being done by Harmony Gold Mining Company Ltd in the Free State region of South Africa is remnant extraction. In the past, remnants were often left along geological structures that were known to be seismically active, or were un-pay blocks of ground. The decision as to the extent and sequence of extraction of these areas can be quite complex. The optimum mining sequence currently takes rock engineering criteria such as energy release rate, average pillar stress, excess shear stress on fault planes, as well as seismic activity, into consideration.

The question arises as to whether these criteria are actually useful in evaluating remnants. In this study it was decided to evaluate average pillar stress, energy release rate, the Mohr-Coulomb failure criterion and hydraulic radius (area of remnant/perimeter of remnant) as possible criteria and analyse the remnants to see if there were any meaningful trends. To determine which remnants should be used for the study, it was decided to evaluate remnants which had adequate seismic coverage and history. In the Free State region it was found that there were only two shafts, Harmony 2 Shaft and Bambanani mine that satisfied these requirements.

\section{Selection of remnants and case studies}

For the case studies, remnants with ample seismic data and relatively good locations were required. This would enable the evaluation of the diurnal distribution for different local magnitudes for these remnants. Only remnants with reported seismic damage were used for the study.

Remnants mined on Bambanani mine and Harmony 2 Shaft, ranging in depths between 1500 and 3200 m, were selected as it was found that these remnants were most problematic and had adequate seismic event data available. Ten remnants were identified where problems such as serious injuries and loss of accessways or equipment due to rockbursts had occurred. Back-analyses were done on these case studies, comparing the rock engineering criteria mentioned above (Le Roux, 2008).

\section{Analysis and results}

In this section the analysis of the results obtained from the case studies is discussed. The results obtained are compared with those currently being used in the mining industry. A new remnant evaluation criterion, the Remnant Failure Index (RFI), was developed for the evaluation of remnants in the Free State, based on the case study results. 


\subsection{Seismic history of case studies}

As part of the evaluation process of the case studies, the seismic history and diurnal distribution of seismic events were evaluated. From this information, it was found that $39 \%$ of seismic events with a local magnitude, $\mathrm{M}_{\mathrm{L}} \geq 1.5$ occurred during the morning shift as shown in Table 1. This was of concern, as production personnel were working at the stope face during this time.

Table 1 Summary of case studies showing diurnal distribution of seismic events ML > 1.5

\begin{tabular}{lccc}
\hline Case Studies Diurnal Distribution & $\begin{array}{c}\text { Day Shift } \\
(6 \mathrm{~h} 00-14 \mathrm{~h} 00)\end{array}$ & $\begin{array}{c}\text { Afternoon Shift } \\
(14 \mathrm{~h} 00-20 \mathrm{~h} 00)\end{array}$ & $\begin{array}{c}\text { Night Shift } \\
(20 \mathrm{~h} 00-6 \mathrm{~h} 00)\end{array}$ \\
\hline Case study 1 & 2 & 3 & - \\
Case study 2 & - & 1 & 1 \\
Case study 3 & 1 & 4 & - \\
Case study 4 & 2 & 3 & 1 \\
Case study 5 & 2 & - & 1 \\
Case study 6 & 3 & 4 & - \\
Case study 7 & - & 2 & - \\
Case study 8 & 6 & 6 & - \\
Case study 9 & 1 & 1 & - \\
Case study 10 & - & - & - \\
Total of 44 events with ML $>1.5$ & 17 & 24 & $6 \%$ \\
$\%$ Distribution & $39 \%$ & $55 \%$ & 3 \\
\hline
\end{tabular}

In Figure 1, the percentage of events with a local magnitude, $\mathrm{M}_{\mathrm{L}} \geq 1.5$ versus the area of the remnant is shown. For the Free State it has been found that damage only starts to occur in remnants when the local magnitude, $\mathrm{M}_{\mathrm{L}} \geq 1.5$ for these events (Le Roux, 2008). The seismic events obtained for the case studies indicated a decrease in seismicity with decreasing remnant area for events with a local magnitude, $\mathrm{M}_{\mathrm{L}} \geq 1.5$, as shown in Figure 1. From Figure 1, remnants $>5350 \mathrm{~m}^{2}$ are most seismically active in the Free State with a sharp drop in seismicity when smaller than this (Le Roux, 2008).

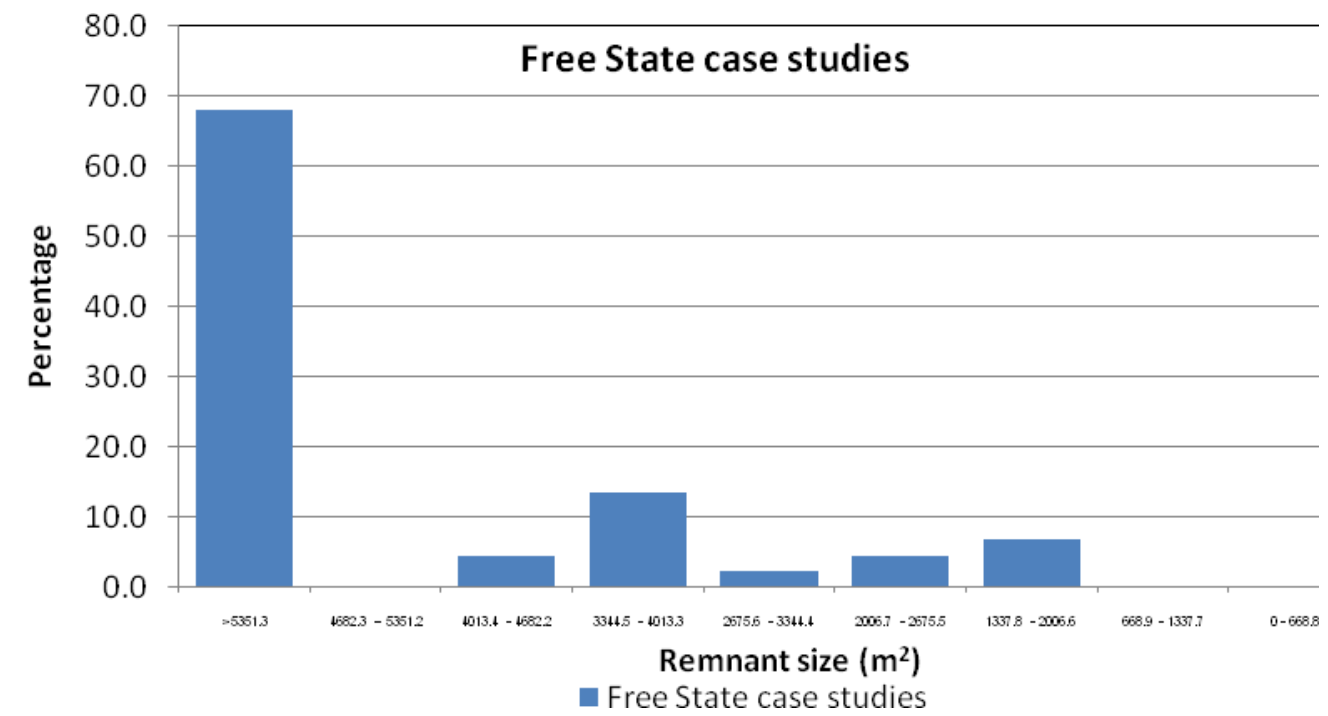

Figure 1 Percentage of damaging seismic events relative to remnant size $\left(\mathrm{m}^{2}\right)$ 


\subsection{Average pillar stress (APS)}

The pillar strength criterion developed for the evaluation of foundation failure of stability pillars (Jager and Ryder, 1999), where APS $<2.5 \sigma_{\mathrm{c}}$, was used to evaluate the case studies. The results obtained were used to assess whether the APS criterion could be applicable for evaluating remnants in the Free State. In Figure 2 the average pillar stress (MPa) is plotted relative to the area of the remnant left to be mined. Limiting values are plotted in Figure 2 for the shale and the average strength for the Waxy Brown Quartzite and Upper Footwall Quartzite. The limiting value used for the shale, with a UCS of $60 \mathrm{MPa}$, is $150 \mathrm{MPa}$. The limiting value used for foundations in Waxy Brown Quartzite and Upper Footwall Quartzite, with an average UCS of $180 \mathrm{MPa}$, is $450 \mathrm{MPa}$. When assuming that the plotted seismic events, $\mathrm{M}_{\mathrm{L}} \geq 1.5$, as shown in Figure 2, indicate failure of the rock, the results indicate that remnants failed well before reaching an average pillar stress of $450 \mathrm{MPa}$. However, for the shale it would appear that failure does occur when the limiting criterion of $150 \mathrm{MPa}$ is exceeded.

It is clearly visible from Figure 2 that there is a significant difference in case studies 1 and 2 done on Harmony 2 Shaft when compared to the rest of the case studies done on Bambanani mine. This is mainly due to the difference in mining span, which is in excess of $400 \mathrm{~m}$, around these two remnants on Harmony 2 Shaft. On Bambanani mine there are numerous north-south geological structures with loss of ground reducing the mining span, which hardly ever exceeds $200 \mathrm{~m}$.

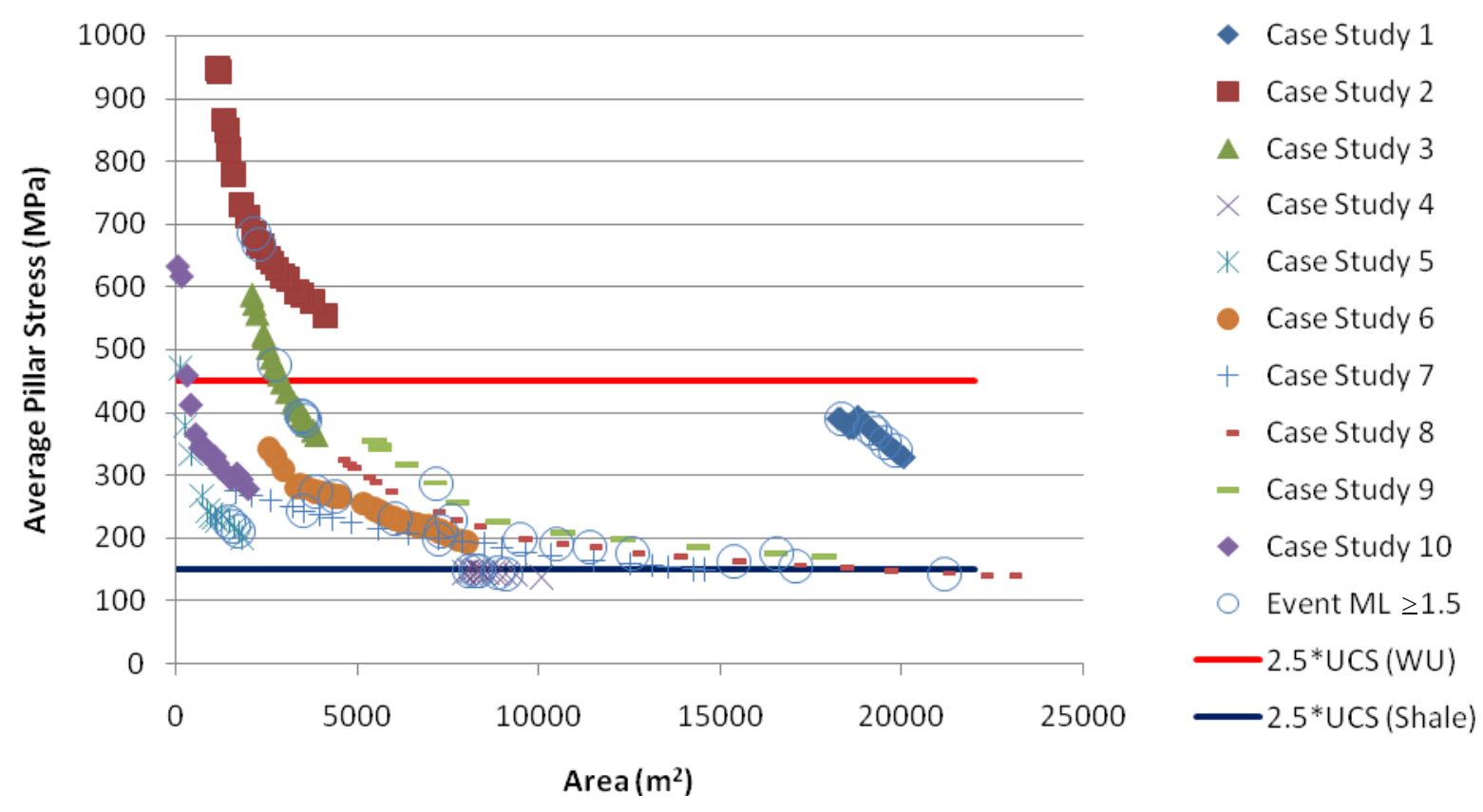

Figure 2 Average pillar stress (MPa) versus area $\left(\mathbf{m}^{2}\right)$

In Table 2 the maximum values obtained for average pillar stress for each case study are listed. From the results, the pillar strength failure criterion is exceeded for $50 \%$ of the case studies. It is probable that the rock mass in the remnant has partially yielded or failed as a result of the very high stresses. 
Table 2 Maximum values obtained for average pillar stress for case studies

\begin{tabular}{lc}
\hline & Maximum APS (MPa) \\
\hline Case study 1 & 393 \\
Case study 2 & 947 \\
Case study 3 & 586 \\
Case study 4 & 1054 \\
Case study 5 & 470 \\
Case study 6 & 343 \\
Case study 7 & 274.4 \\
Case study 8 & 324.9 \\
Case study 9 & 353.5 \\
Case study 10 & 632 \\
\hline
\end{tabular}

The pillar strength criterion is mainly used for the evaluation of bord and pillar mining, pillar punching into the foundation and foundation failure of stabilising pillars, and not for remnants. It is concluded that the use of the pillar strength criterion for remnants is unsatisfactory, due to the continuous change in dimensions of the remnant during mining. Stabilising pillars are designed with specific dimensions, and once created, will remain intact for the life of mine. The average pillar stress results were relatively scattered for the remnants and thus could be ascribed to the difference in mining span, shape of remnants and depth below surface (Le Roux, 2008).

\subsection{Energy release rate (ERR)}

Energy release rate is a parameter that is used in the evaluation of mining layouts. Since its introduction in the 1960s it remains to this day the most acceptable parameter measuring the severity of conditions in deep mining (Jager and Ryder, 1999).

In Figure 3 the seismic events recorded versus the energy release rate are plotted for the West Rand mines, Southern Free State and Central Rand mines (Jager and Ryder, 1999). The data plotted in Figure 3 are from four longwall mines prior to the introduction of stabilising pillars.

The number of seismic events, $\mathrm{M}_{\mathrm{L}} \geq 1$, recorded per $1000 \mathrm{~m}^{2}$ stoped in the Free State, plotted against ERR in Figure 3 (b), indicates that with increase in ERR there is an increase in the number of events. The conclusion was drawn from four case studies in the Free State that, with increase in ERR, seismicity increases. It is however clear that the ERR values obtained in the Free State are extremely high when compared to the other regions. To be consistent, the same approach was taken in the present research: in Figure 4 the number of seismic events, $\mathrm{M}_{\mathrm{L}} \geq 1$, recorded per $1000 \mathrm{~m}^{2}$ stoped in the ten case studies, is plotted against ERR. No trend was found from the results. 


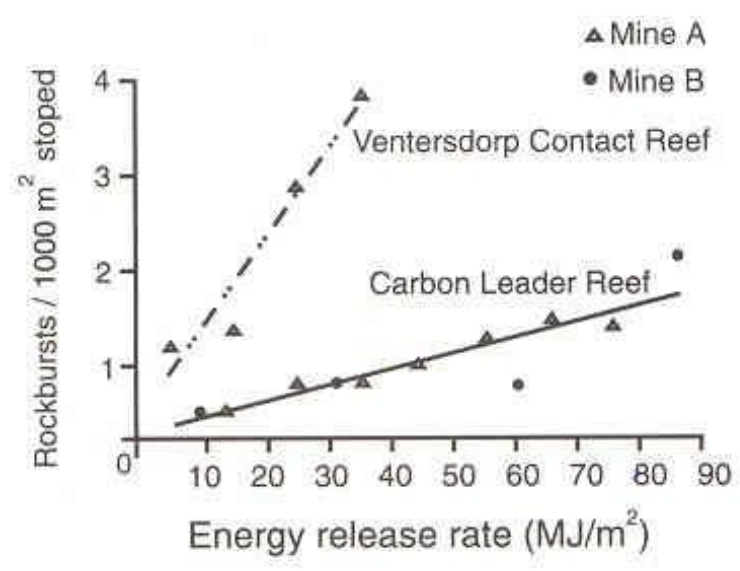

(a) Far West Rand Mines
홍

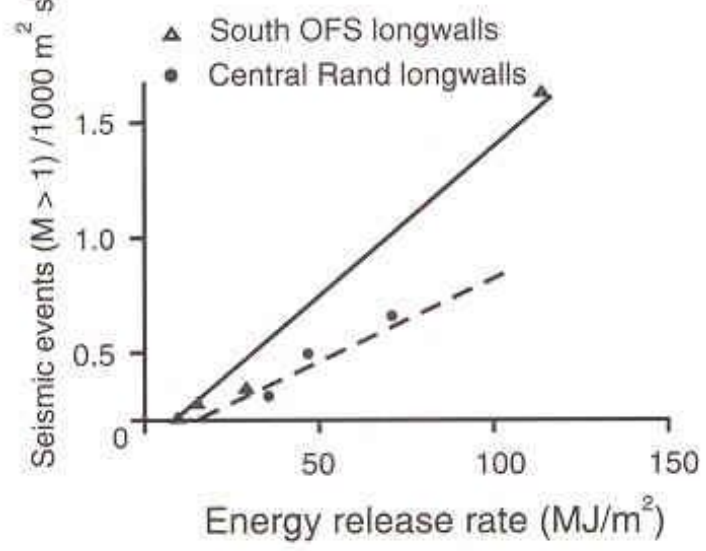

(b) Southern O.F.S and Central Rand Mines

Figure 3 Rockburst and seismicity versus ERR. Data from four longwall mines prior to the introduction of stabilising pillars (Jager and Ryder, 1999)

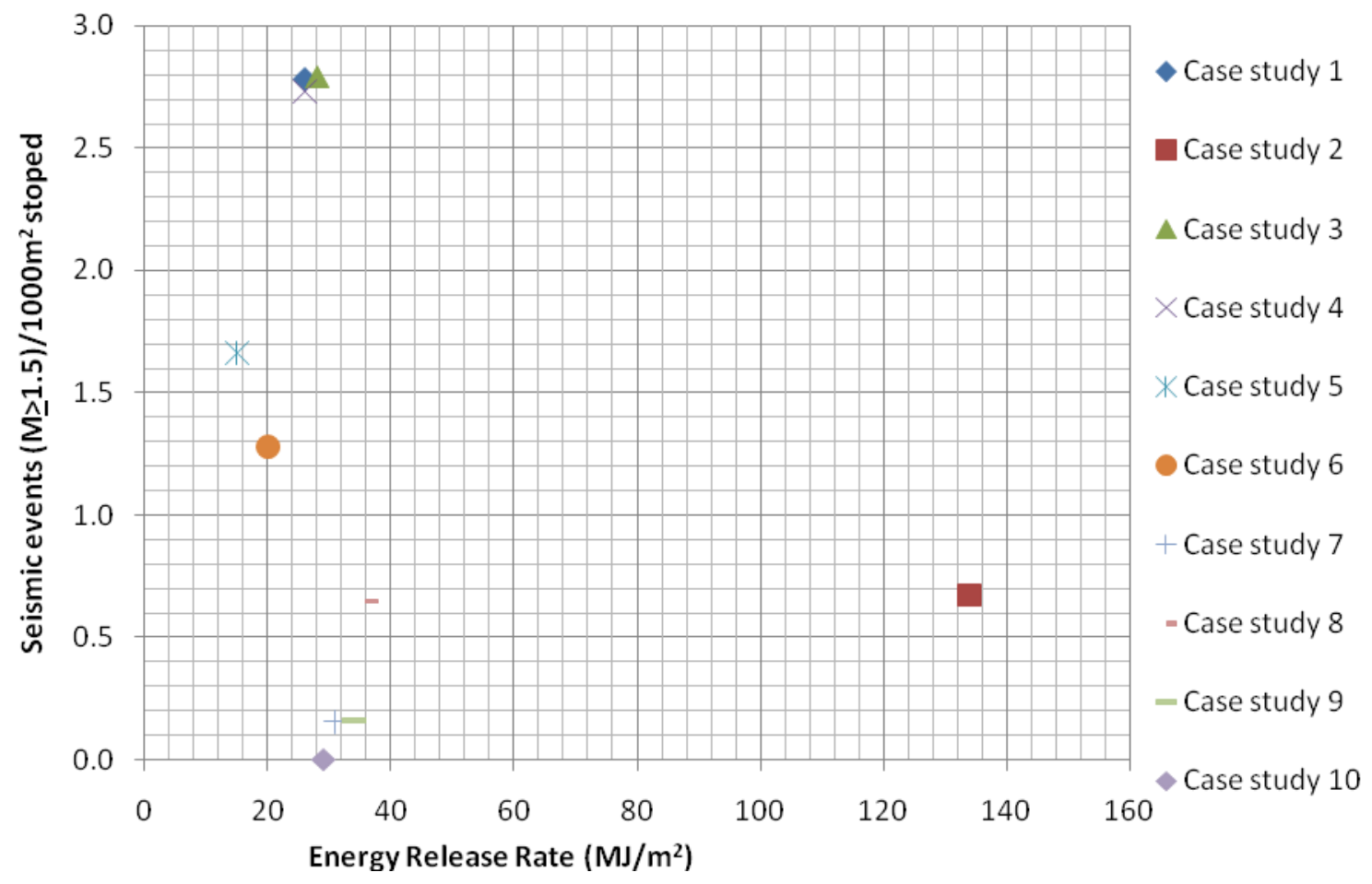

Figure 4 Seismic events $(M \geq 1.5)$ versus ERR when mining remnants

In Figure 5 the ERR is plotted for each mining step relative to the area of the remnant left to be mined. Assuming that the plotted seismic events, $\mathrm{M}_{\mathrm{L}} \geq 1.5$ as shown in Figure 5, indicate failure of the rock, the results indicated that $68 \%$ of the remnants failed before reaching the commonly acceptable limit of $30 \mathrm{MJ} / \mathrm{m}^{2}$ (Jager and Ryder, 1999). The results obtained for these remnants are scattered and no trend could be determined. On Harmony 2 Shaft it was found that the average ERR at the stope face was extremely high and this could be ascribed to the excessive mining spans during the numerical analysis and therefore the high stresses and closures calculated elastically. 
For remnants on Bambanani mine it was found that the average energy release rate did not exceed $60 \mathrm{MJ} / \mathrm{m}^{2}$. Although much greater than the $30 \mathrm{MJ} / \mathrm{m}^{2}$ as recommended (Jager and Ryder, 1999), no major face bursting was recorded or reported in these case studies.

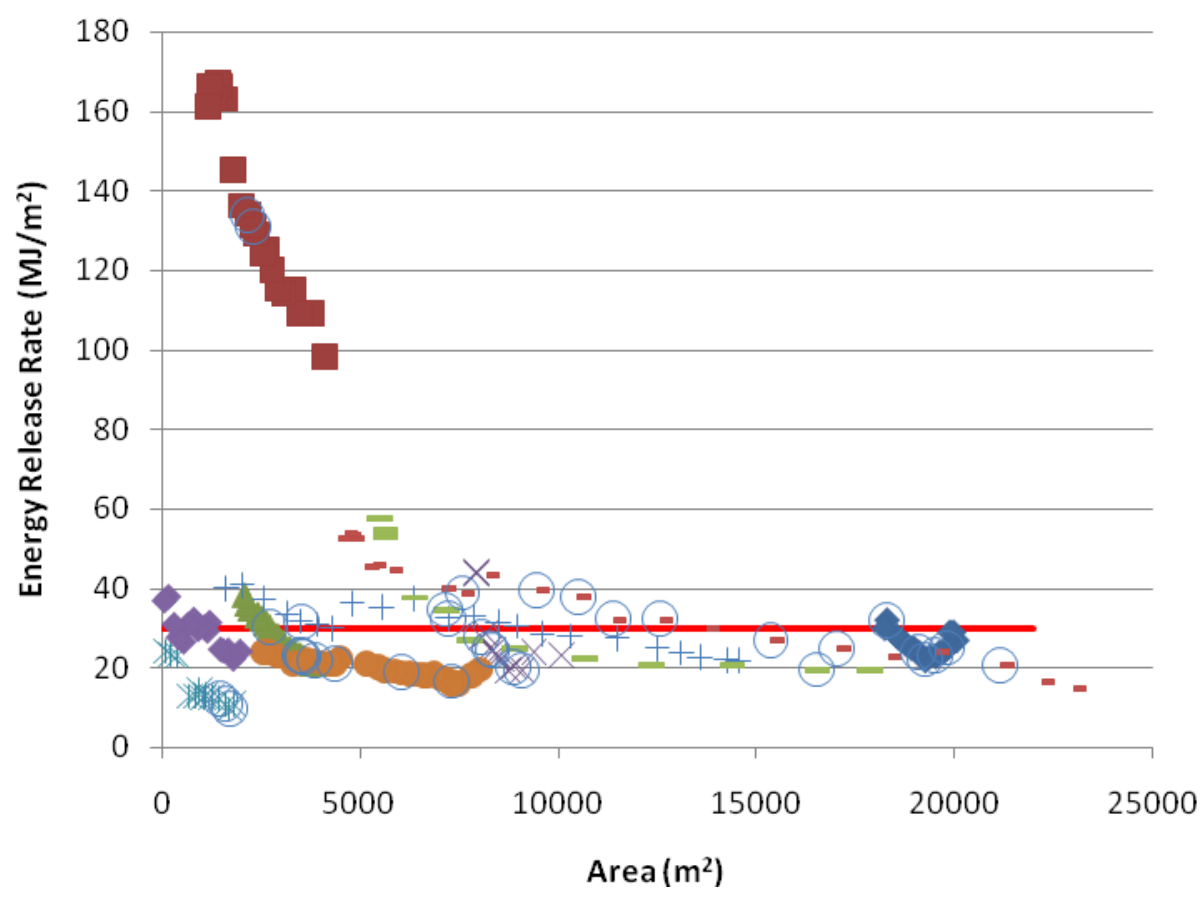

- Case Study 1

- Case Study 2

A Case Study 3

$\times$ Case Study 4

* Case Study 5

- Case Study 6

+ Case Study 7

- Case Study 8

- Case Study 9

- Case Study 10

Event MP 1.5

$-30 \mathrm{MJ} / \mathrm{m}$

\section{Figure 5 Energy release rate $\left(\mathrm{MJ} / \mathrm{m}^{2}\right)$ versus Area $\left(\mathbf{m}^{2}\right)$}

In Table 3, the maximum values obtained for energy release rate for each case study are listed. From the results, the common energy release rate criterion of $30 \mathrm{MJ} / \mathrm{m}^{2}$ is exceeded for $80 \%$ of the case studies.

Table 3 Maximum value for energy release rate for case studies

\begin{tabular}{lc}
\hline & Maximum ERR $\left(\mathrm{MJ} / \mathrm{m}^{2}\right)$ \\
\hline Case study 1 & 32 \\
Case study 2 & 167 \\
Case study 3 & 38.2 \\
Case study 4 & 44.2 \\
Case study 5 & 24.2 \\
Case study 6 & 24.2 \\
Case study 7 & 40.7 \\
Case study 8 & 53.7 \\
Case study 9 & 57.5 \\
Case study 10 & 38 \\
\hline
\end{tabular}




\subsection{Hydraulic radius}

Remnants are generally irregularly shaped making it difficult to compare them with each other, as stated by Hill (1944). Hydraulic radius (area/perimeter), also known as the shape factor, describes the size of a block of ground to be mined (Brown, 1997). Hydraulic radius is predominantly used in massive mining operations for the estimation of caveability. By using hydraulic radius (area/perimeter) to describe the shape of a remnant, it was expected that it might be possible to compare remnant behaviour.

In Figure 6 the number of seismic events, $\mathrm{M}_{\mathrm{L}} \geq 1.5$, recorded per $1000 \mathrm{~m}^{2}$ stoped at the ten case studies, is plotted against hydraulic radius. No trend was found from the results, as shown in Figure 6.

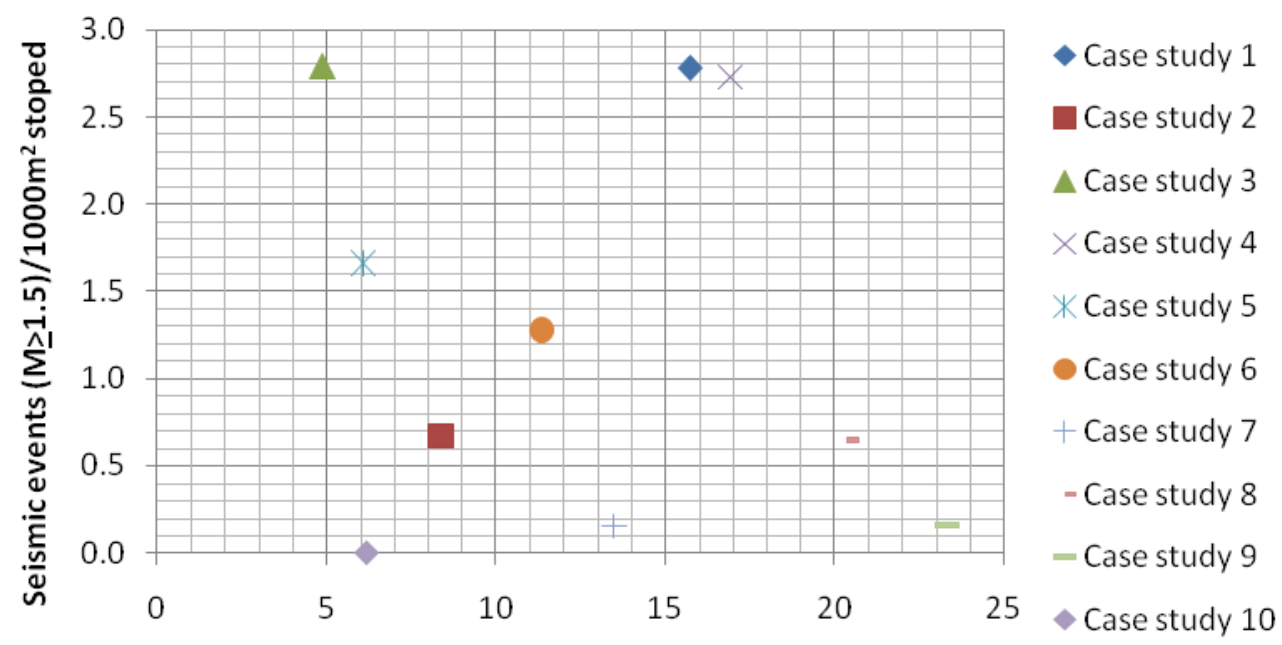

Hydraulic Radius

Figure 6 Seismic events $(M \geq 1.5)$ versus hydraulic radius when mining remnants

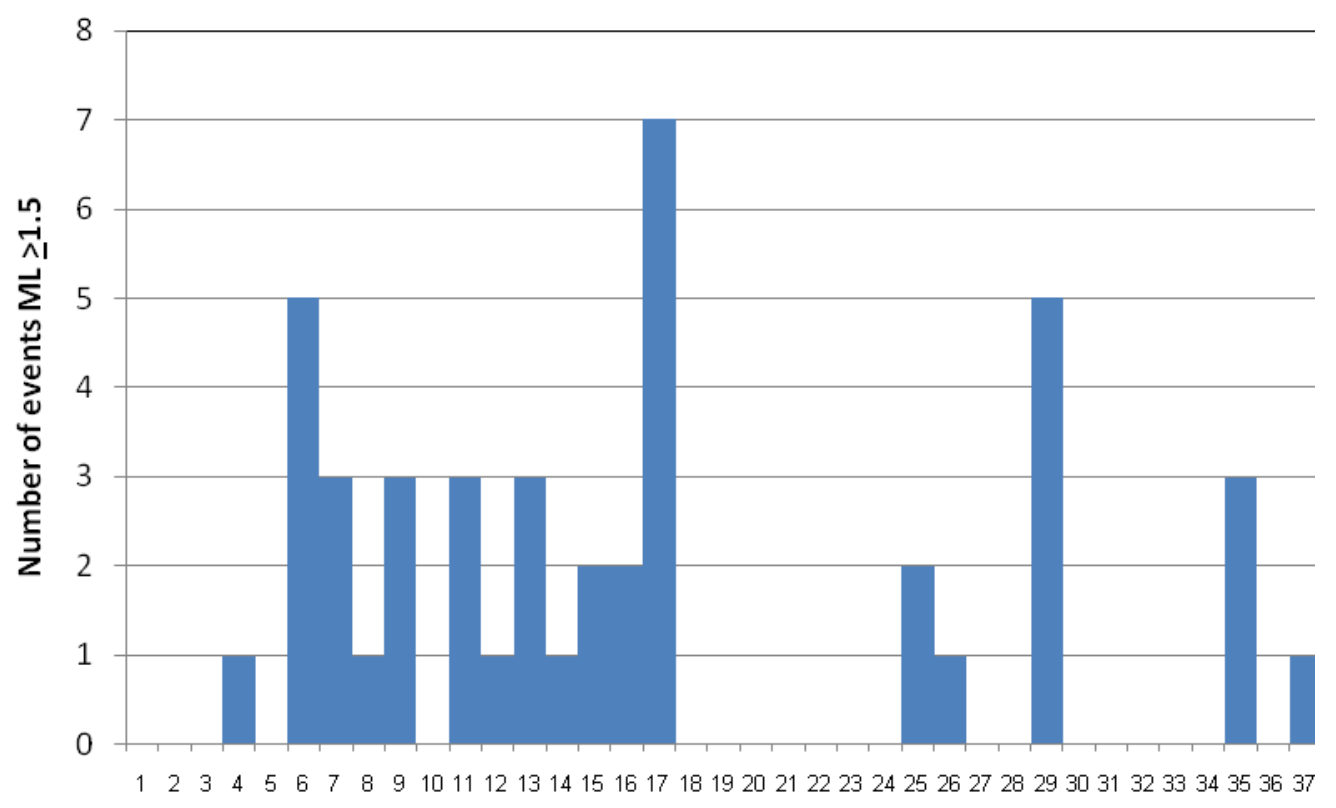

Hydraulic Radius

Figure 7 Number of events versus hydraulic radius 
Figure 7 shows the distribution of seismic events relative to hydraulic radius. From these results there is no indication of a correlation between hydraulic radius and the occurrence of seismic events in remnants. This is most probably due to the fact that the remnants may be completely fractured or crushed. It is concluded that hydraulic radius is not a satisfactory criterion for the evaluation of remnants in the Free State.

\subsection{Mohr-Coulomb failure criterion}

The Mohr-Coulomb criterion, which can be mathematically expressed as in Equation 1 (Wiles, 2006), was used to evaluate the case studies.

$$
\sigma_{1}=q \sigma_{3}+\sigma_{c}
$$

Where $\sigma_{1}$ and $\sigma_{3}$ represent, respectively, the major and minor principal stresses, $\sigma_{\mathrm{c}}$ and $q$ represent, respectively, the rock mass unconfined compressive strength and slope of the best fit-line, and where:

$$
q=\tan ^{2}\left(45+\frac{\varphi}{2}\right) ; \varphi \text { is the friction angle }
$$

To evaluate the failure criterion for the failure of remnants, the $\sigma_{1}$ and $\sigma_{3}$ values for a given seismic event that occurred at specific coordinates $(\mathrm{x}, \mathrm{y}$ and $\mathrm{z}$ ) for given mining steps were substituted into the equation. From these data a failure criterion for remnants was determined. Failure is defined as follows:

$$
\text { where } \frac{\sigma_{1}}{\left(q \sigma_{3}+\sigma_{\sigma}\right)} \text { is greater than 1, failure will occur. }
$$

The assumption is that seismic events actually represent failure of the remnant. For this study only events with a local magnitude, $\mathrm{M}_{\mathrm{L}} \geq 1.5$ within the remnant were used. The reason for using only seismic events with a local magnitude, $\mathrm{M}_{\mathrm{L}} \geq 1.5$ is that with these events damage was usually observed.

In a MAP3D numerical model, the $\sigma_{1}$ and $\sigma_{3}$ stress values at specific coordinates (x,y and $\mathrm{z}$ ) for the seismic events, at the respective mining steps, were obtained. In Figure 8 the $\sigma_{1}$ and $\sigma_{3}$ stress values obtained from the analyses are plotted for each seismic event. When plotting all the $\sigma_{1}$ and $\sigma_{3}$ values obtained, it was found that there is a strong correlation between the prevailing stresses at the time of each seismic event. From these values a failure criterion describing the failure of remnants in the Free State could be derived, which is described by $\sigma_{1}=2.12 \sigma_{3}+5.56$ as shown in Figure 8 .

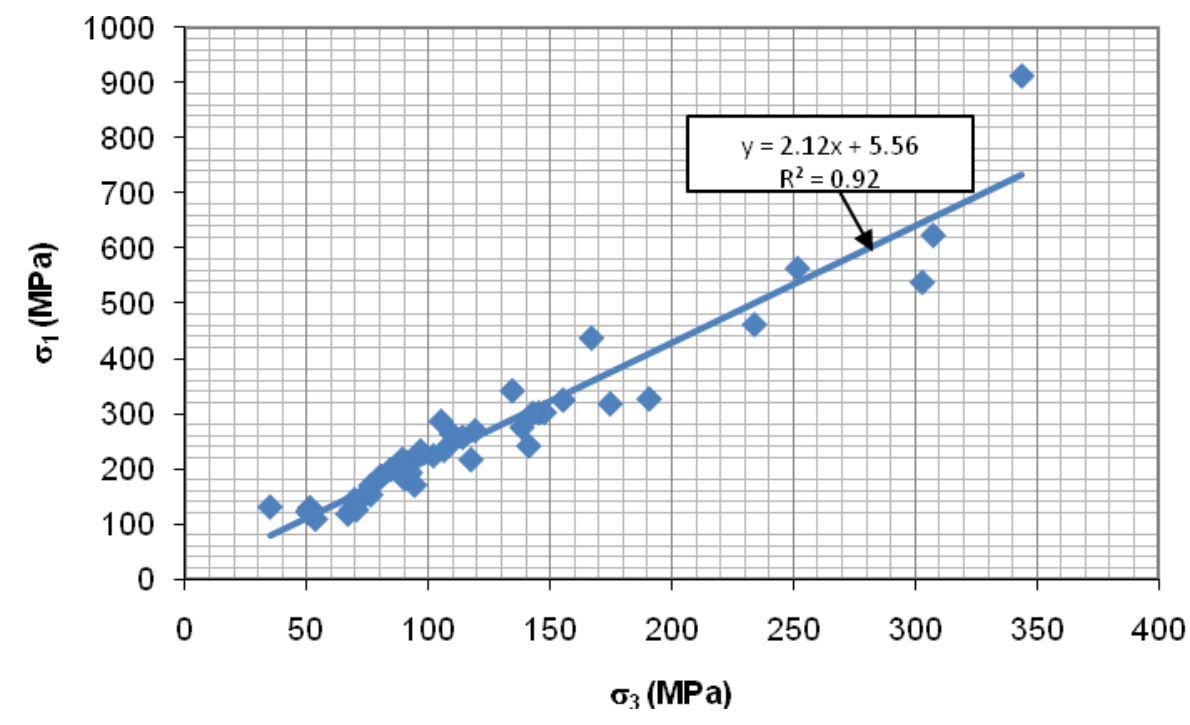

Figure 8 Sigma 1 versus sigma 3 values obtained from analysis 
Using the linear trend line, one finds that the mean error in prediction of $\sigma_{1}$ is approximately $45 \mathrm{MPa}$. This gives a coefficient of variation of $17 \%$ as shown in Table 4 , which is considered to be an acceptable variability (Wiles, 2006).

Table 4 Sigma 1 and Sigma 3 values obtained from the stress analyses

\begin{tabular}{ccc|ccc}
\hline$\sigma_{1}(\mathrm{MPa})$ & $\sigma_{3}(\mathrm{MPa})$ & $\Delta \sigma_{1}(\mathrm{MPa})$ & $\sigma_{1}(\mathrm{MPa})$ & $\sigma_{3}(\mathrm{MPa})$ & $\Delta \sigma_{1}(\mathrm{MPa})$ \\
\hline 146.21 & 69.86 & 7.45 & 563.94 & 251.63 & -24.92 \\
342.98 & 134.62 & -52.03 & 129.38 & 68.78 & 22.00 \\
438.16 & 167.08 & -78.40 & 276.67 & 138.62 & 22.77 \\
218.85 & 89.46 & -23.64 & 243.35 & 141.34 & 61.85 \\
128.02 & 70.67 & 27.35 & 319.34 & 174.77 & 56.72 \\
623.86 & 307.30 & 33.19 & 302.82 & 145.57 & 11.35 \\
538.69 & 302.79 & 108.78 & 171.43 & 76.57 & -3.55 \\
270.83 & 119.38 & -12.19 & 303.72 & 147.77 & 15.11 \\
462.44 & 233.97 & 39.13 & 326.06 & 155.46 & 9.08 \\
265.68 & 109.65 & -27.65 & 194.83 & 92.83 & 7.53 \\
911.58 & 343.65 & -177.48 & 302.40 & 142.99 & 6.31 \\
328.09 & 190.74 & 81.84 & 187.80 & 80.75 & -11.06 \\
111.07 & 53.87 & 8.69 & 235.28 & 106.55 & -3.83 \\
124.65 & 50.90 & -11.17 & 201.07 & 84.77 & -15.80 \\
188.05 & 80.54 & -11.75 & 234.06 & 97.01 & -22.84 \\
131.85 & 51.64 & -16.80 & 259.01 & 114.31 & -11.11 \\
119.93 & 67.16 & 28.00 & 172.71 & 94.50 & 33.19 \\
125.78 & 50.89 & -12.34 & 213.96 & 91.28 & -14.89 \\
121.88 & 51.25 & -7.66 & 133.11 & 35.27 & -52.77 \\
184.05 & 90.33 & 13.02 & 154.96 & 76.50 & 12.79 \\
151.96 & 73.44 & 9.30 & 287.91 & 105.41 & -58.88 \\
218.41 & 117.68 & 36.64 & 225.60 & 102.24 & -3.29 \\
\hline $\bar{\sigma}_{1}=263.46$ & & $q=2.12$ & & & \\
$\bar{\sigma}_{3}=121.63$ & & & & & \\
$s_{1}=157.96$ & & & & & \\
$s_{3}=71.48$ & & & & & \\
$s=45.11$ & & & & & \\
\hline & & & & & \\
\hline
\end{tabular}




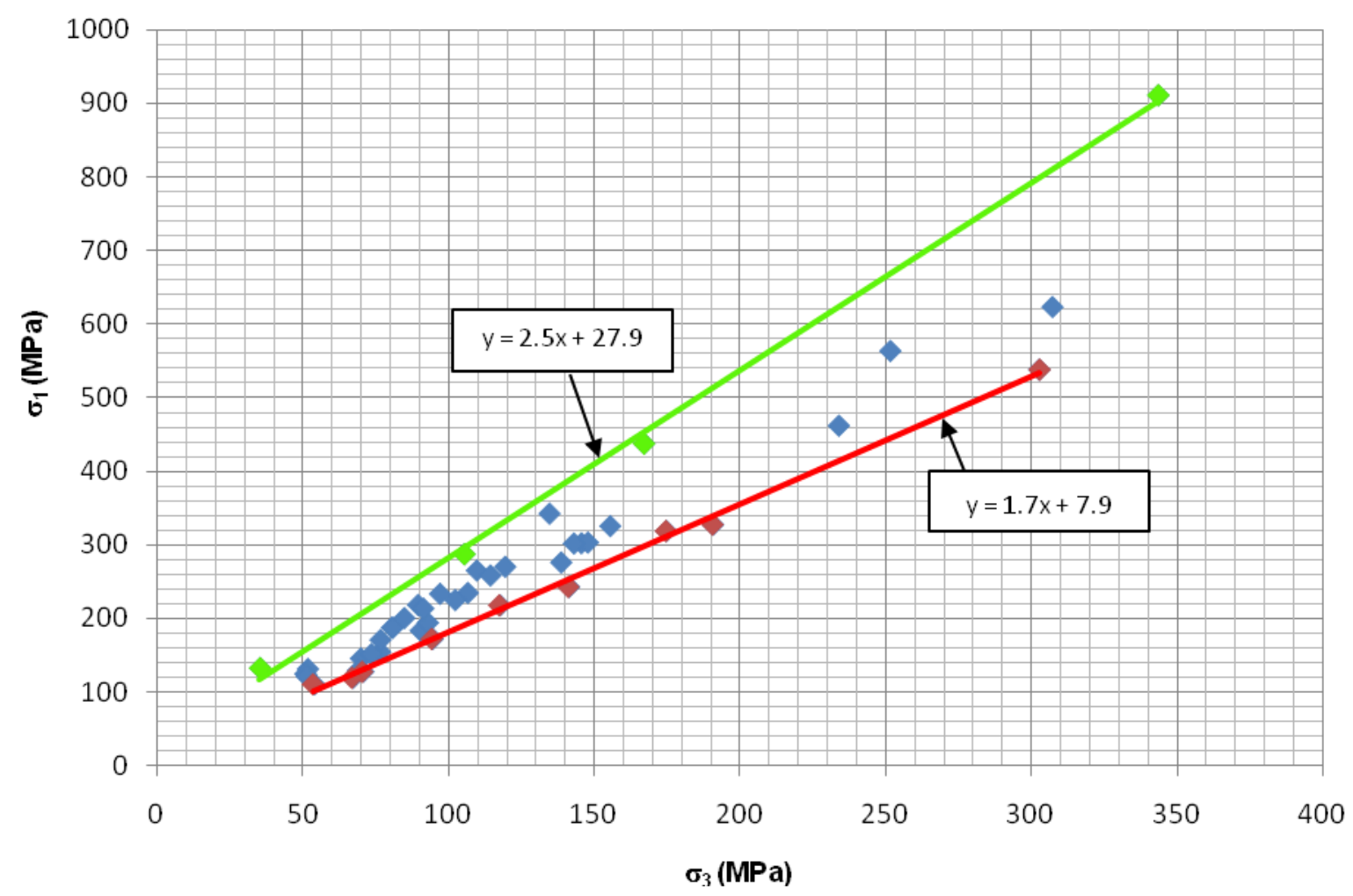

\section{Figure 9 Upper and lower limit trend lines obtained from the analyses}

The failure criterion $\sigma_{1}=2.12 \sigma_{3}+5.56$ describes the overall behaviour of the remnant case studies in the Free State. The scatter in the results allows upper and lower limits to the data to be defined, as shown in Figure 9. The lower limit is expressed as $\sigma_{1}=1.7 \sigma_{3}+7.9$ and the upper limit is expressed as $\sigma_{1}=2.5 \sigma_{3}+27.9$.

Based on this criterion, a guideline for the safe extraction of remnants is proposed. This guideline only applies to mining of remnants in the Free State region. Lines defining upper and lower limits can be drawn describing the behaviour of remnants in the Free State as shown in Figure 10. When the $\sigma_{1}$ and $\sigma_{3}$ stresses in a remnant are plotted on this chart, remnant stability conditions can be defined as described below.

Stable remnants can be described as follows:

$$
\frac{\sigma_{1}}{\left(1.7 \sigma_{3}+7.9\right)}<1 \text {, i.e. situated below the lower limit trend line. }
$$

Violent remnant failure (potential occurrence of rockbursts) can be described as follows:

$\frac{\sigma_{1}}{\left(1.7 \sigma_{3}+7.9\right)}>1<\frac{\sigma_{1}}{\left(2.5 \sigma_{13}+27.9\right)}$, i.e. situated between the upper and lower limit trend lines.

Non violent failure (crushing) of remnants can be described as follows:

$\frac{\sigma_{1}}{\left(2.5 \sigma_{3}+27.9\right)}>1$, i.e. situated above the upper limit trend line. 


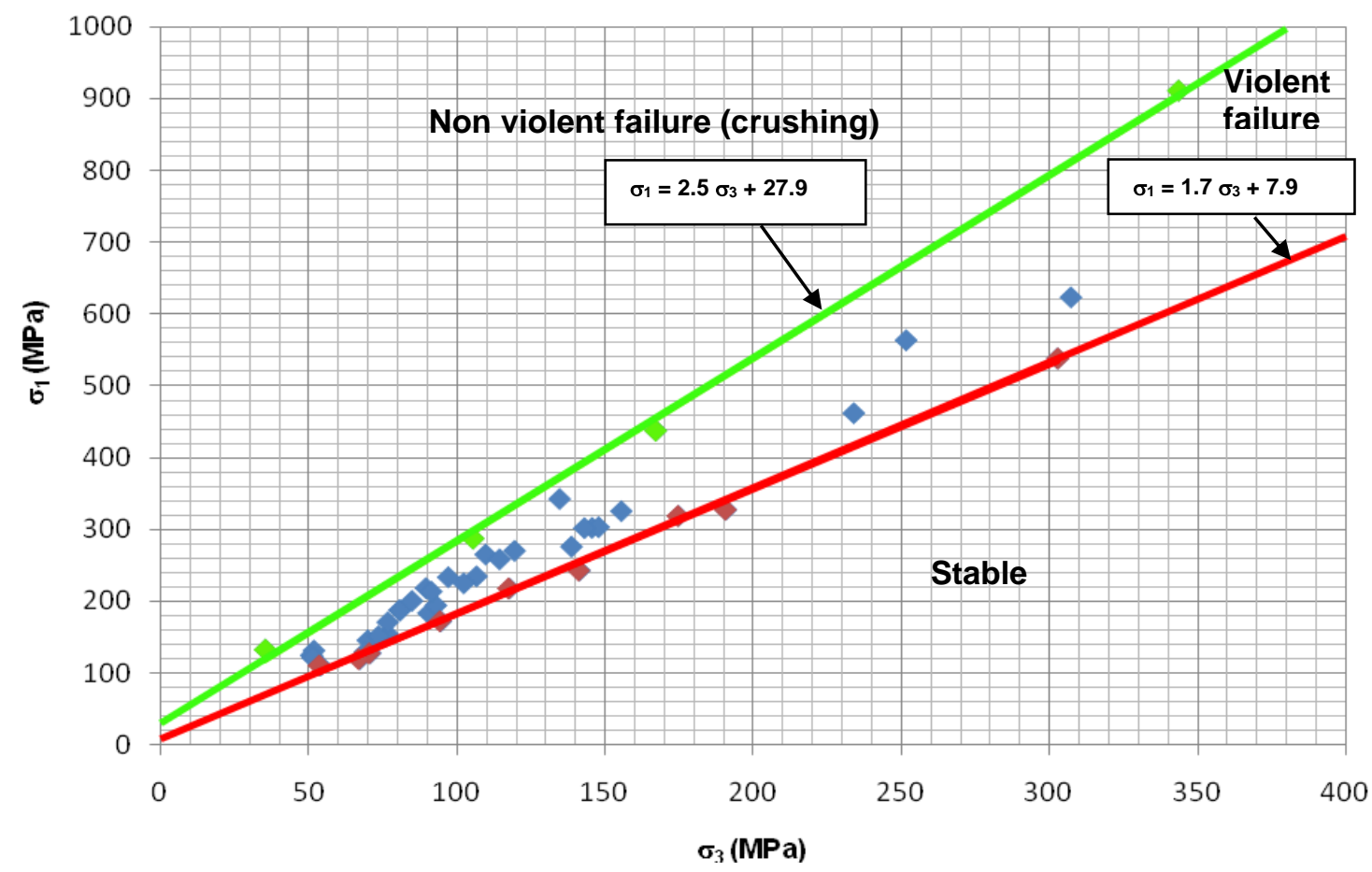

Figure 10 Upper and lower limits for remnant failure in the Free State

The non-violence results since the remnant has already failed. However, it would be unwise to design for a failed pillar in this region of the Figure 10 as it might fail violently before it reaches the state of crushing.

The upper and lower limits enable the practitioner to model the proposed mining layout for the remnant and identify possible areas within the remnant where failure can occur. The remnant failure index (RFI) (Le Roux, 2008), based on the Mohr-Coulomb failure criterion, is proposed as a criterion to evaluate the potential occurrence of rockbursts at remnants.

When the RFI $=\frac{\sigma_{1}}{\left(1.7 \sigma_{3}+7.9\right)}$ is greater than 1 the remnant will fail violently

$$
\text { When the RFI }=\frac{\sigma_{1}}{\left(2.5 \sigma_{3}+27.9\right)}
$$

is greater than 1 the case study results show that the potential occurrence of rockbursts is no longer possible.

Table 5 is a summary of how the behaviour of these remnants can be predicted using the following remnant failure indices.

Table 5 Showing behaviour of remnants in Free State for different remnant failure indexes

\begin{tabular}{ll}
\hline Remnant Behaviour & Remnant Failure Index \\
\hline Stable & $\frac{\sigma_{1}}{\left(1.7 \sigma_{3}+7.9\right)}<1$ \\
Violent failure & $\frac{\sigma_{1}}{\left(1.7 \sigma_{3}+7.9\right)}>1<\frac{\sigma_{1}}{\left(2.5 \sigma_{3}+27.9\right)}$ \\
$\begin{array}{l}\text { Non violent failure } \\
\text { (crushing) }\end{array}$ & $\frac{\sigma_{1}}{\left(2.5 \sigma_{3}+27.9\right)}>1$ \\
\hline
\end{tabular}


It is to be noted that the validity of the back analysis approach must depend on the accuracy with which the seismic events have been located, since the $\sigma_{1}$ and $\sigma_{3}$ stresses are determined at those locations from the MAP3D analyses. If the location accuracy is poor, then the stresses will be inaccurate. In spite of this caveat, the correlation shown previously is remarkably good.

\section{Application of the remnant failure index}

In this section, the application of the proposed remnant failure index (RFI) will be discussed and it will be demonstrated how the results obtained from numerical analyses of remnants can be implemented. Figure 11 shows the sequence of events followed and how remnants can be evaluated using the RFI.

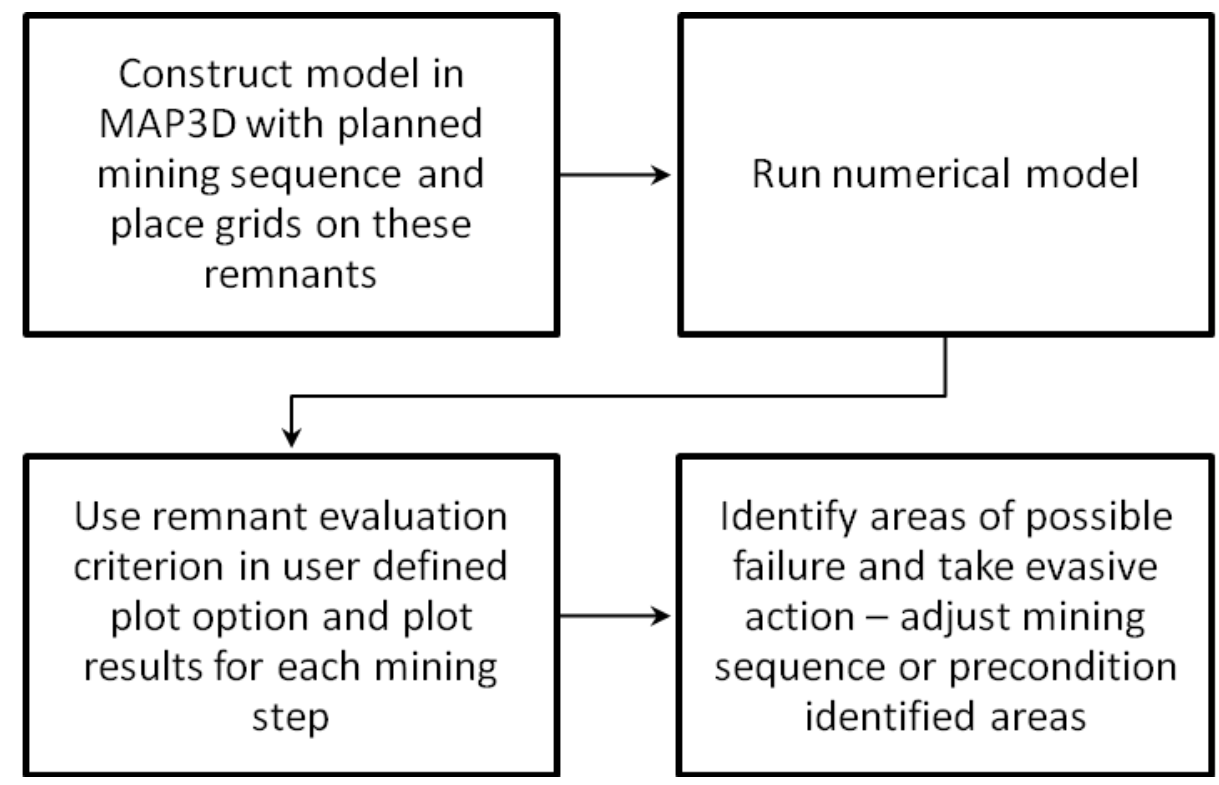

Figure 11 Sequence of events for modelling remnants and applying the remnant failure index

Using the RFI for evaluating the potential occurrence of rockbursts

$$
\mathrm{RFI}=\frac{\sigma_{1}}{\left(1.7 \sigma_{3}+7.9\right)}
$$

Areas where this criterion is exceeded, and are therefore most susceptible to failure, can be identified. Although areas can be identified where the potential for dynamic failure exists, the actual time or current mining configuration when these seismic events may occur, is still not known. The lobe of possible failure indicated is of great assistance as it enables the practitioner to determine the most probable position of failure and resulting seismicity. Suitable methods of addressing and reducing the hazard can then be applied which can include:

- Implementation of preconditioning (Toper et al., 1998).

- Deciding on the extent of remnant extraction (percentage extraction).

- Considering the best layout.

- Reviewing the mining sequence and choosing the most appropriate one.

\section{$5 \quad$ Future work}

Future research should investigate whether there is any correlation between the Local Energy Release Density (LERD) and $\sigma_{3}$. It is recommended that future research should also evaluate the applicability of the 
approach described in other mining areas such as the West Wits area within South Africa. Future research could also be carried out on the RFI to determine whether there is any correlation between the areas of the possible failure lobes obtained and seismic event magnitudes.

\section{Conclusions}

The results of the study suggest that the use of average pillar stress, energy release rate and hydraulic radius is ineffective for the evaluation of the potential dynamic failure of remnants. However, the proposed remnant evaluation criterion, the Remnant Failure Index (RFI), based on the Mohr-Coulomb failure criterion, has been proposed. This index will only apply to mining of remnants in the Free State region. The method should also only be applicable where dynamic failure is expected to be associated with the failure of the remnant. Where failure could occur on a geological feature, the criterion may not be applicable.

When analysing the $\sigma_{1}$ and $\sigma_{3}$ results obtained for each seismic event at the time of the event, it was found that there was a strong correlation between the stress states in the remnant, which can be described by the failure criterion $\sigma_{1}=2.12 \sigma_{3}+5.56$, which represents the overall behaviour of the remnant case studies in the Free State. The scatter in the results allows upper and lower limits to the data to be defined. The lower limit is expressed as $\sigma_{1}=1.7 \sigma_{3}+7.9$ and the upper limit is expressed as $\sigma_{1}=2.5 \sigma_{3}+27.9$. Using RFI as a criterion to evaluate the rockburst failure of remnants, it was found that when the RFI $=\sigma_{1} /\left(1.7 \sigma_{3}+7.9\right)$ is greater than 1 , the remnant will fail violently. When the RFI $=\sigma_{1} /\left(2.5 \sigma_{3}+27.9\right)$ is greater than 1 , the case study results show that violent remnant failure no longer occurs.

The RFI enables the practitioner to model proposed mining layouts for remnant extractions and identify possible areas or lobes within the remnants where violent failure may occur. Although areas can be identified where seismic events are likely to be located, the actual time or mining step when these events may occur is not known. The identification of areas of possible failure could allow preconditioning to be used to destress the rock. Alternatively, by modelling different mining scenarios and comparing them, revised mining sequences and layouts of the remnants may be considered. The application of the RFI to each alternative will indicate which alternative is to be preferred.

\section{Acknowledgements}

The authors wish to thank the management of Harmony Gold for permission to publish this article. Furthermore, the management of Brentley Lucas and Associates (Pty) Ltd is thanked for encouragement in the preparation of this material.

\section{References}

Brown, E.T. (1997) Block Caving Geomechanics, The International Caving Study I 1997 - 2000, JKMRC Monograph Series in Mining and Mineral Processing 3, pp. 127-138.

Hill, F.G. (1944) A System of Longwall Stoping in a Deep-Level Mine, with Special Reference to its Bearing on the Pressure Burst and Ventilation Problems. Association of Mine Managers of the Transvaal, Papers and Discussions, 1942-1945, Vol. 1, pp. 257-276.

Jager, A.J. and Ryder, J.A. (editors) (1999) A Handbook on Rock Engineering Practice for Tabular Hard Rock Mines. The Safety in Mines Research Advisory Committee (SIMRAC), Johannesburg.

Le Roux, P.J. (2008) The Extraction of Existing Remnant Blocks of Ground at Harmony Gold Mine's Free State Operations, MSc Eng Research Report submitted to the Faculty of Engineering and the Built Environment, University of the Witwatersrand, Johannesburg.

Toper, A. Z., Stewart, R. D., Kullmann, D. H., Grodner, M., Lightfoot, N., Janse van Rensburg, A. L. and Longmore, P. J. (1998) Develop and Implement Preconditioning Techniques to Control Face Ejection Rockbursts for Safer Mining in Seismically Hazardous Areas, GAP336 Final Report, CSIR Division Mining Technology.

Wiles, T.D. (2006) Reliability of Numerical Modelling Predictions, International Journal of Rock Mechanics and Mining Sciences, Vol. 43, pp. 454-472. 
